\title{
Study on natural oils as alternative processing aids and activators in carbon black filled natural rubber
}

\author{
W.G.D. Jayewardhana ${ }^{1}$, G.M. Perera ${ }^{2}$, D.G. Edirisinghe ${ }^{2}$ and L. Karunanayake ${ }^{1^{*}}$ \\ I Department of Chemistry, Faculty of Applied Science, University of Sri Jayewardenepura, Gangodawila, Nugegoda. \\ 2 Rubber Research Institute of Sri Lanka, Telawala Rd., Ratmalana.
}

Revised: 01 April 2009; Accepted: 15 May 2009

\begin{abstract}
The potential of naturally available oils as additives instead of processing aids and activators in carbon black filled natural rubber was investigated in this study. Physical properties and cure characteristics of the vulcanizates containing the natural oils were compared with those of the standard vulcanizate which was prepared using an aromatic oil. Soybean oil, palm oil and sunflower oil were selected as the natural oils and used at a fixed dose (5phr) in the compounding process as processing aids. The natural oils were incorporated in the compounding process, to examine their potential as activators and processing aids simultaneously. The results indicate that soybean oil, palm oil and sunflower oil are better alternative processing aids than petroleum based aromatic oils which have been reported to be carcinogenic. In addition, palm oil has the best heat resistance ability. Further, the cure characteristics and mechanical properties of the vulcanizate based on soybean oil suggest that it could be used as a co-activator for rubber compounding.
\end{abstract}

Keywords: Mechanical properties, processing aid, rubber, vegetable oils, vulcanization.

\section{INTRODUCTION}

Processing aids used in rubber compounding provide lubrication between rubber molecules and facilitate the processing of the polymer during milling and mixing. They also improve the physical properties of natural and synthetic rubber such as elasticity, flex life, low temperature performance, and aid in the dispersion of pigments resulting in improvement of tensile strength and abrasion resistance ${ }^{1,2}$.

Conventional processing aids such as aromatic processing oils have been reported to be carcinogenic ${ }^{3,4}$. The use of non toxic plant based materials such as rice bran oil $(\mathrm{RBO})^{5}$ and epoxidized derivative of rice bran oil (ERBO) $)^{3,4}$ in place of aromatic oils has been reported. It has been reported that rice bran oil can replace aromatic oil, antioxidant and the fatty acid components of the sulphur vulcanization formula of natural rubber (NR) without much effect on the cure characteristics and physical properties of the vulcanizate 5 . In the latter, the oils have been used as processing aids in NRpolychloroprene blends and it has been shown that they could replace aromatic oils ${ }^{3,4}$.

The use of vegetable oils or plant based oils in rubber compounding in various capacities has been reported by large number of researchers ${ }^{3-11}$. The effect of palm oil fatty acids in two different vulcanization systems on the cure characteristics and physical properties has already been reported ${ }^{6}$. Kundu et al. have studied various aspects of the use of vegetable oils in carbon black filled NR compounds such as the effect of oils on carbon black/rubber interaction ${ }^{7,9}$ and the effect of surface modification of carbon black by vegetable oils ${ }^{8}$. The use of palm oil fatty acid as an activator in carbon black filled compounds has been reported giving special attention to dynamic properties and curing characteristics ${ }^{11}$. These findings support the possible use of non-toxic vegetable oils as alternatives to aromatic based processing oils, while highlighting the positive effect of them on cure characteristics and other properties of vulcanizates produced.

The use of tyres which contain polycyclic aromatic hydrocarbons (PAH) in their formula will be banned in European countries by the end of $2009^{12}$. Hence, alternatives to these $\mathrm{PAH}$ containing processing aids have to be found. The alternatives chosen should not only be non-toxic, but they should also have properties which are 
in -par with the properties of currently used $\mathrm{PAH}$ rich processing oils. These properties are related to road and passenger safety of the transportation industry.

\section{METHODS AND MATERIALS}

As a preliminory study the possibility of using soybean oil (SYBO), palm oil (PMO) and sunflower oil (SFO) as processing aids in a tyre tread compound was studied. Cost and availability of the alternative oils were considered as the key parameters, while the natural oils which have closer chemical composition to rice bran oil were selected, based on the argument that they will also act as good processing aids and activators for natural rubber based products. Compositions of SYBO and SFO are very similar to that of RBO. PMO was also selected as the oleic acid percentage of PMO is similar to that of RBO. Further, cure characteristics were monitored to find their potential use as a part of the activator systems.

The natural rubber used in this study was RSS 3 grade obtained from Sri Lanka. Zinc oxide, stearic acid, CBS (N-cyclohexylbenzthiazylsulphenamide), carbon black (HAF N 330), processing oil (Dutrex R-aromatic processing oil), IPPD (N-isopropyl-N'-phenyl-pphenylenediamine) and sulphur used were of industrial grade and were obtained from the retail rubber chemical suppliers of Colombo.

SYBO oil and PMO used in this study were commercial products of Ngo Chew Hong Edible Oil (Pvt.) Ltd. and SFO was a product of Sime Darby Edible Products Ltd. Oils were of edible commercial grades and used without further purification.

Wij's solution, sodium thiosulphate 5-hydrate $\left(\mathrm{Na}_{2} \mathrm{~S}_{2} \mathrm{O}_{3} \cdot 5 \mathrm{H}_{2} \mathrm{O}\right)$ and potassium dichromate were procured from Loba Chemie (Pvt) Ltd. Glacial acetic acid was procured from BDH Chemicals. Hydrochloric acid, carbon tetrachloride and toluene were purchased from the retail chemical suppliers in Colombo. All other

Table 1: Tyre tread formulation

\begin{tabular}{lc}
\hline Material & Quantity/ phr $^{*}$ \\
\hline Natural rubber (RSS) & 100.0 \\
ZnO (rubber grade) & 5.0 \\
Stearic acid (rubber grade) & 2.0 \\
Carbon black (HAF N 330) & 50.0 \\
Processing oil [Dutrex R (NMO) or vegetable oil] & 5.0 \\
IPPD (N-isopropyl-N'-phenyl-p-phenylenediamine & 1.5 \\
Sulphur & 2.5 \\
CBS (N-cyclohexybenzthiazylsulphenamide) & 1.5 \\
\hline
\end{tabular}

* $1 \mathrm{phr}=1$ part by weight per 100 parts by weight of rubber chemicals used were of analytical grade unless specified otherwise.

Rubber compound preparation: The tyre tread formulation given in Table 1 was used as the standard formulation throughout the research.

Accurately weighed vulcanizing ingredients were compounded using a lab scale Banbury mixer and a two roll mill according to the formulation given in the Table 1. This process was repeated for SYBO, PMO, $\mathrm{SFO}$ and standard aromatic oil (NMO).

Curing test: The curing characteristics were measured using an Oscillating Disk Rheometer (ODR) operated at $150^{\circ} \mathrm{C}$ according to ASTM D 2084-81 ${ }^{9}$.

Molding: Vulcanized rubber sheets were compression molded using a hydraulic press at a temperature of $150^{\circ} \mathrm{C}$ and a pressure of $20 \mathrm{MPa}$. The cure time was calculated for each compound using $\mathrm{t}_{90}$ value obtained.

\section{Measurement of physical and mechanical properties:}

a) Swelling Index: From each type of vulcanizate $3 \mathrm{~cm} \mathrm{x}$ $1 \mathrm{~cm} \times 2 \mathrm{~mm}$ specimens were prepared, weighed $\left(\mathrm{w}_{\mathrm{i}}\right)$ using an analytical balance and the results recorded. Then, the samples were immersed separately in toluene. The samples were kept for few days and weighed regularly until a constant weight was observed $\left(\mathrm{w}_{\mathrm{s}}\right)$. Swelling index was calculated according to Equation (1).

Swelling index $=\left(\mathrm{w}_{\mathrm{s}}-\mathrm{w}_{\mathrm{i}}\right) / \mathrm{w}_{\mathrm{i}}$

b) Tensile properties: Dumbbell-shaped test samples were cut from the molded sheets. Tensile properties were measured using a Hounsfield tensile testing machine according to ISO $37: 1994(E)$ at a cross head speed of $500 \mathrm{~mm} \mathrm{~min}^{-1}$.

c) Hardness: Hardness values were determined with a Shore-A Pocket hardness tester as described in ISO 48:1994(E).

d) Tear strength: For tear strength, crescent shaped test pieces were punched out, nicked and the Hounsfield tensile testing machine was used to obtain tear strength values according to ISO 34-1:1994(E).

e) Rebound resilience: Rebound resilience was measured using a Lüpke Pendulum according to the test method given in ISO 4662-1986(E).

f) Abrasion mass loss $\%$ : The mass loss due to abrasion was evaluated with a Din Abrader according to DIN 53516 . 
g) Compression set: Test pieces were compressed for $72 \mathrm{~h}$ at room temperature and the measurements were carried out according to ISO 815:1991(E).

h) Ageing properties: Ageing studies were carried out to evaluate aged tensile strength and tear strength according to ISO 188:1998(E). The samples were aged in an ageing oven at $100^{\circ} \mathrm{C}$ for $22 \mathrm{~h}$.

i) Flex cracking resistance: The evaluation of flex cracking resistance was carried out according to ISO 132:2005 test method using De Mattia flexometer.

Table 2: Cure characteristics of carbon black filled NR vulcanizates produced with different types of natural oils.

\begin{tabular}{lccccc}
\hline $\begin{array}{c}\text { Processing } \\
\text { aid }\end{array}$ & $\begin{array}{c}\text { Scorch } \\
\text { time/min }\end{array}$ & $\begin{array}{c}\text { Cure time/ } \\
\text { min }\end{array}$ & $\begin{array}{c}\text { Cure rate } \\
\text { index }\end{array}$ & $\begin{array}{c}\text { Maximum torque } \\
\text { value/d Nm }\end{array}$ & $\begin{array}{c}\text { Delta cure } \\
\left(\mathrm{M}_{\mathrm{H}}-\mathrm{M}_{\mathrm{L}}\right) / \mathrm{d} \mathrm{Nm}^{\mathrm{a}}\end{array}$ \\
\hline NMO & 1.79 & 7.41 & 17.79 & 169.22 & 148.13 \\
SYBO & 2.03 & 9.7 & 13.04 & 258.69 & 223.63 \\
PMO & 2.17 & 9.51 & 13.62 & 199.95 & 172.61 \\
SFO & 2.44 & 10.26 & 12.79 & 142.14 & 124.64 \\
\hline
\end{tabular}

${ }^{\mathrm{a}}: \mathrm{M}_{\mathrm{H}}$ - Maximum torque and $\mathrm{M}_{\mathrm{L}}-$ Minimum torque

Table 3: Tensile strength (before ageing) of the compounds with different processing oils

\begin{tabular}{lc}
\hline Processing aid & $\begin{array}{c}\text { Tensile strength } \\
\text { (before ageing) MPa }\end{array}$ \\
\hline NMO & 23.95 \\
SYBO & 22.57 \\
PMO & 22.54 \\
SFO & 23.63 \\
\hline
\end{tabular}

Table 5: Hardness of the compounds prepared with different processing oils.

\begin{tabular}{cc}
\hline Processing aid & Hardness \\
\hline & 63 \\
NMO & 64 \\
SYBO & 61 \\
PMO & 63 \\
SFO & \\
\hline
\end{tabular}

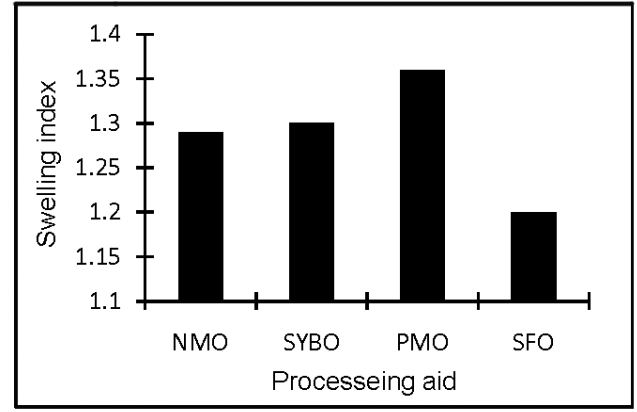

Figure 1: Variation of swelling index with type of processing oil
Table 4: Tensile strength (after ageing) of the compounds with different processing oils

\begin{tabular}{lc}
\hline Processing aid & $\begin{array}{c}\text { Tensile strength } \\
\text { (after ageing)MPa }\end{array}$ \\
\hline NMO & 17.61 \\
SYBO & 17.20 \\
PMO & 17.97 \\
SFO & 18.05 \\
\hline
\end{tabular}

Table 6: Tear strength of the compounds prepared with different processing oils.

\begin{tabular}{lcc}
\hline Processing aid & $\begin{array}{c}\text { Tear strength } \\
\text { (before ageing) } \\
\text { N/mm }\end{array}$ & $\begin{array}{c}\text { Tear strength } \\
\text { (after ageing) } \\
\text { N/mm }\end{array}$ \\
\hline NMO & 149.00 & 130.11 \\
SYBO & 147.22 & 127.28 \\
PMO & 148.18 & 130.25 \\
SFO & 149.25 & 130.62 \\
\hline
\end{tabular}

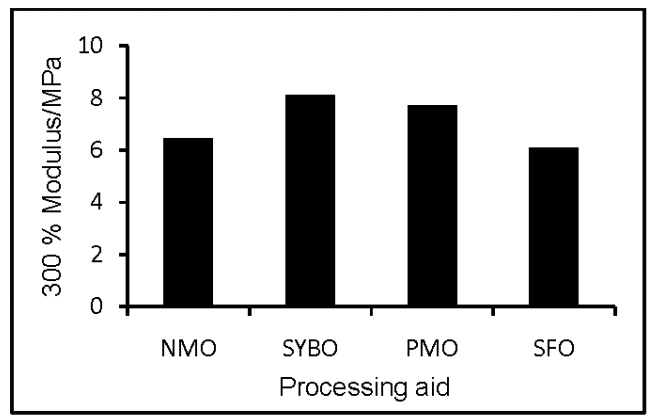

Figure 2: Variation of $300 \%$ Modulus with processing oil 


\section{RESULTS}

\section{Curing behaviour}

Cure characteristics of the tyre tread compounds prepared with the four oils under study are given in Table 2.

The vulcanization system used was a conventional vulcanization (CV) system where in the tyre tread formulation the sulphur to accelerator (CBS) ratio used was 2.5:1. In CV systems, relative percentages of polysulphide, disulphide and monosulphide crosslinks are $70 \%, 15 \%$, and $15 \%$ respectively ${ }^{7}$. Hence, $t_{90}$ was chosen as the cure time to prevent the breakage of relatively weak polysulphide linkages during the final stages of the vulcanization process.

Variation of swelling index of the compounds prepared with the four oils is shown in Figure 1. Variation of $300 \%$ modulus and the tensile strength values of the compounds prepared with the four oils are shown in the Figure 2 and Table 3, respectively. Tensile properties determined after ageing at $100^{\circ} \mathrm{C}$ for $22 \mathrm{~h}$ and percentage retention of tensile strength after ageing are given in Table 4 and Figure 3, respectively. Hardness values of the tyre tread compounds prepared with the four oils are given in Table 5.

Tear strength (before and after ageing) and the retention of tear strength of the vulcanizates after ageing prepared with different oils are given in Table 6 and Figure 4, respectively.

\section{DISCUSSION}

According to Table 2, the highest scorch time was recorded for the sample that contains SFO as the processing aid, while the lowest was recorded for the sample with standard aromatic oil. In general, three vegetable oils have recorded higher scorch times indicating better processing safety in comparison to the standard aromatic oil when incorporated in the carbon-black filled tyre tread formulation. Similar observations have been reported for palm oil fatty acids when incorporated in carbon black filled NR compounds for both $\mathrm{CV}$ and semi-CV systems ${ }^{6,11}$. Further, the results confirm that palm oil based fatty acids impart a retardation effect on CV systems ${ }^{9}$.

In the case of cure rate index values, NMO sample has recorded the highest value while all three vegetable oils have reported a value close to 13 (Table 2). This indicates a retarding effect on the rate of vulcanization by the three oils incorporated. However, Kuriakose and Varghese $^{3}$ have reported a cure-accelerating effect for the NR/Polychloroprene blend compounds containing RBO and ERBO. This cure-accelerating effect could be due to the effect of polar pendant Chlorine atom attached to the polychlorprene molecule.

While the best maximum torque and delta cure values of the compounds were given by the SYBO, PMO also has recorded values higher than those of NMO containing compound. This indicates that the crosslink densities of vulcanizates of compounds containing SYBO and PMO are higher than those of compounds containing NMO. However, Kundu et al. ${ }^{8,9}$ have reported that the rheometric torque obtained is low for compounds containing a vegetable oil (proprietary chemical) mixture. In addition, Ismail et al. ${ }^{11}$ have reported that the torque depends on both fatty acid content and carbon black content in the compound.

\section{Swelling index}

Generally, swelling index is inversely proportional to the cross-link density ${ }^{3}$. Therefore, one would expect a relationship between the delta cure $\left(M_{H}-M_{L}\right)$ value and the swelling index. Such a relationship cannot be observed from the results given in Table 2 and from the Figure 1. The reason for this different behaviour of the results is probably due to swelling restriction in the presence of carbon black. However, the effect of fillers on swelling is relatively small compared with the effect of the rubber. Boonstra and Dannenberg have noted that the decrease in matrix swelling is an almost linear function of the loading, with carbon black ${ }^{13}$. Further, matrix swelling will also depend on the degree of dispersion of carbon black. At any given oil level, the degree of dispersion of the black is influenced by the type of oil used. It has been reported that aromatic oil gives the best dispersion followed by naphthenic and paraffinic materials in that order ${ }^{2}$. Delta cure of SYBO and PMO is higher than that of NMO and hence a higher swelling index is expected for NMO. However, the swelling index of NMO is lower than that of SYBO and PMO. The reason may be due to better dispersion of carbon black with aromatic $\mathrm{NMO}^{2}$, which results in a greater restriction to swelling.

\section{Tensile properties}

Modulus expresses resistance to extension, or stiffness in vulcanizate ${ }^{14}$. It can be observed that the pattern of change of modulus in Figure 2 is similar to that of delta cure values of Table 2, i.e. $\mathrm{SYBO}>\mathrm{PMO}>\mathrm{NMO}>$ SFO. These results are in agreement with each other as both are related to the cross-link density. 


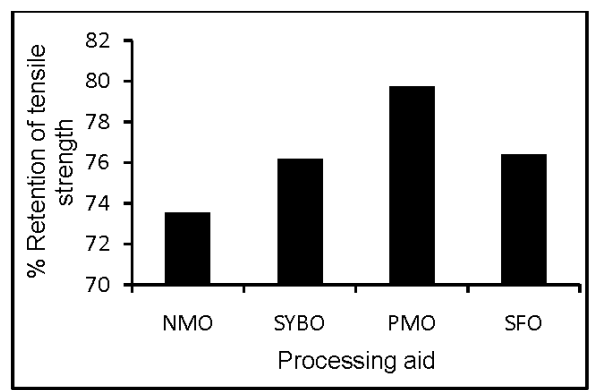

Figure 3: Variation of \% retention of tensile strength with type of processing oil

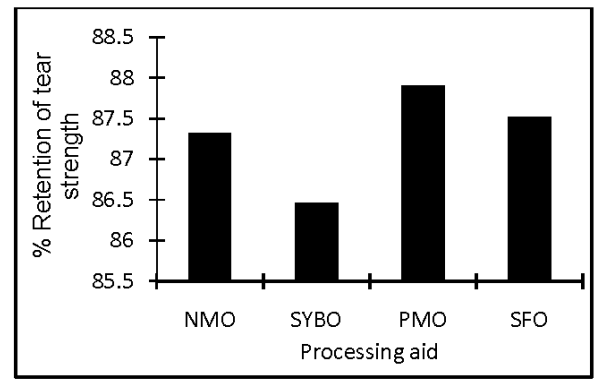

Figure 5: Variation of elongation at break with type of processing oil

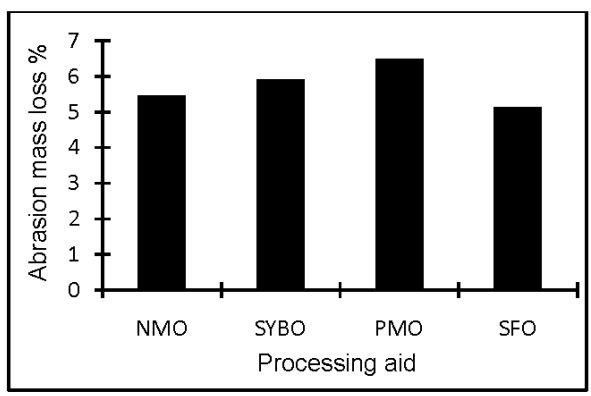

Figure 7: Variation of abrasion mass loss with type of processing oil

Both cross-link type and degree of cross-linking have a significant effect on tensile strength of natural rubber. According to Table 3 , the highest tensile strength value was given by the vulcanizate with aromatic oil, but the other natural oil vulcanizates have also shown comparatively good tensile strength values. SFO with somewhat lower cross-link density also produced a vulcanizate with a somewhat higher tensile strength value.

According to Figure 3, while the highest percentage retention of tensile strength after ageing is reported by $\mathrm{PMO}$, the other two oils also show retention values higher than that of the aromatic oil. It seems that the

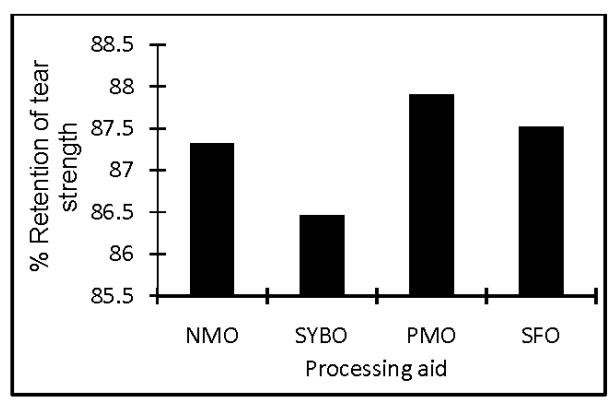

Figure 4: Variation of $\%$ retention of tear strength with type of processing oil

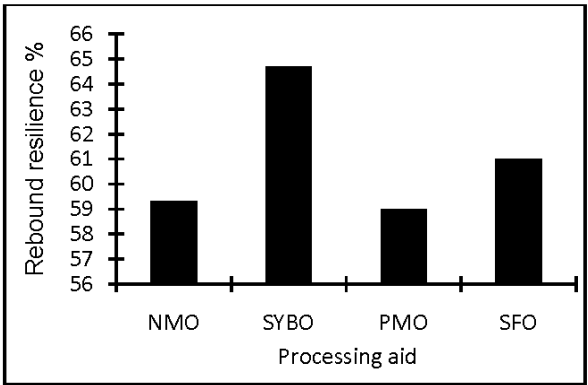

Figure 6: Variation of rebound resilience with type of processing oil

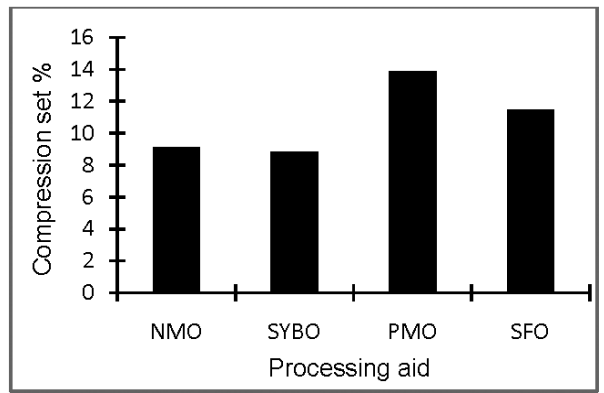

Figure 8: Variation of compression set with type of processing oil

natural oils have improved thermal stability of the rubber vulcanizates.

As shown in Table 5, vulcanizate with the highest hardness is produced by the compound prepared with SYBO which has also shown the highest maximum torque and the highest maximum cross-link density. However, the results indicate that there is no considerable difference among the hardness values of the compounds prepared with the four oils.

The highest value for tear strength is for the vulcanizate that contains SFO (Table 6). According to 
the delta cure values given in Table 2, though SFO has lower amount of cross-links in comparison to SYBO and PMO, it has shown better tensile and tear properties in the vulcanizates. This may be due to facilitation of dispersion of carbon black by SFO and hence better reinforcement imparted compared to the other two natural oils.

According to Figure 4, the best percentage retention of tear strength value is shown by the vulcanizate prepared with $\mathrm{PMO}$, while the lowest is recorded by the vulcanizate prepared with SYBO. As in the case of percentage retention of tensile strength, the vulcanizate containing PMO shows the highest value for percentage retention of tear strength. This confirms the increased thermal stability of vulcanizate containing PMO.

The trend of change of the elongation at break is in the opposite direction of the trend observed in the Figure 2 (i.e. $\mathrm{SFO}>\mathrm{NMO}>\mathrm{PMO}>\mathrm{SYBO}$ ). This is in agreement with the earlier argument as the elongation at break is inversely proportional to the cross-link density.

In rubber, resilience is a measure of energy dissipated as heat ${ }^{13}$. If the elasticity is higher, less energy is dissipated as heat. According to Figure 6, the highest resilience has been recorded by the vulcanizate that contains SYBO. According to the Table 2 and Figures 2 and 5, the highest cross-link density was observed for SYBO. Hence, higher storage modulus and lower loss modulus values can be anticipated for the vulcanizate that contains SYBO as reflected in the resilience results. However, the trend cannot be seen in other three vulcanizates, as the lowest resilience value is recorded by PMO instead of SFO.

According to Figure 7, the abrasion mass losses recorded for vulcanizates containing four oils are close to each other. However, the trend shown is similar to that of tear strength results. While the lowest percentage abrasion mass loss was recorded for the SFO, the highest value was recorded for the PMO vulcanizate. This could be explained by the better dispersion of carbon black by SFO compared to SYBO and PMO in the rubber matrix and hence, higher reinforcement as evidence in the case of variation of tensile and tear strength, too.

According to Figure 8, the lowest and the second lowest compression set values are shown by the vulcanizates of SYBO and NMO and they are closer to each other. The highest value is recorded by PMO. This is consistent with the retention of tear strength (Figure 4).

During dynamic loading of vulcanizates (i.e. compression, tension, bending), cracks are formed on the surface. As given in Table 7, natural oil vulcanizates as well as the standard aromatic oil vulcanizate did not show a single pin prick even after 15,000 cycles. This indicates that all four vulcanizates exhibit good resistance to flex cracking.

Carbon black is used in rubber compounding as a reinforcing filler. It is generally accepted that surface property of the filler is one of the most important factors that influence the reinforcing effect in rubber. There are groups such as phenol, carboxyl and lactones on the carbon black surfaces ${ }^{7}$. Vegetable oils are unsaturated long chain fatty acid esters. These oils take part in dual interactions. The polar end of the chain could interact with the carbon black surface, whereas the non-polar unsaturation-rich end could interact with the natural rubber molecules. Therefore, the interaction between hydrocarbon rubbers and carbon black can be improved greatly by the introduction of the coupling action of vegetable oils ${ }^{7,9}$.

Properties such as modulus, hardness, resistance to swelling by solvents and resilience increase with cross-link density whilst some properties such as tensile strength, tear strength, abrasion resistance may decrease with an increase in cross-link density above a certain level ${ }^{15}$.

According to literature, soybean oil ${ }^{16}$ and sunflower oil ${ }^{17}$ have higher and similar unsaturation content, albeit, in this study, soybean oil showed the highest cross-link density (Table 2). In spite of the fact that palm oil does not contain such a high amount of unsaturation ${ }^{7}$, both palm oil and sunflower oil have shown remarkably good curing characteristics in the vulcanization process and physical properties in the vulcanizates (Tables $2 \& 3$ and Figures 1-8).

According to the results, the highest values for the cross-link density (Table 2), hardness (Table 5), 300\% modulus (Figure 2) and \% resilience (Figure 6) are recorded for soybean oil vulcanizates. Soybean oil could have imparted a plasticizing effect to the rubber polymer increasing the freedom of movements of the polymer chains due to breakdown of the polymer-polymer

Table 7: Number of cycles required for the first pin-prick to appear

\begin{tabular}{lc}
\hline Processing aid & Number of cycles \\
\hline NMO & $>15,114$ \\
SYBO & $>20,562$ \\
PMO & $>15,114$ \\
SFO & $>20,562$ \\
\hline
\end{tabular}


interactions ${ }^{16}$. Thereafter, the dual interaction of soybean oil can take place between the elastomer chains and carbon black particles facilitating dispersion of carbon black aggregates ${ }^{9,10}$.

It could be envisaged that two different phenomena affect the properties of carbon black filled vulcanizates. That is, while the facilitation of coupling action between the filler and the polymer via unsaturated oil can improve properties of a vulcanizate, increase of free volume of polymer through plasticization can improve properties further by increasing the dispersion of the filler in the compound.

\section{CONCLUSION}

It is suggested that the three vegetable oils studied can be used as processing aids without any adverse effect on the properties of the vulcanizates produced. The results indicate that soybean oil, palm oil and sunflower oil are better alternative processing aids in place of petroleum based aromatic oils which have been reported as carcinogenic. In addition, palm oil has the best heat resistance ability. Further, the cure characteristics and mechanical properties of the vulcanizate based on soybean oil further suggest that it could be used as a coactivator for rubber compounding.

\section{Referneces}

1. Hofmann W. (1989). Rubber Technology Handbook. Hanser Publishers, Vienna, Italy.

2. Whelan A. \& Lee K.S. (1979). Improving product Performance. In: Developments in Rubber Technology-1. Applied Science Publishers Ltd. London, UK.

3. Kuriakose A.P. \& Varghese M. (2003). Use of rice bran oil and epoxidized rice bran oil in carbon black-filled natural rubber-polychloroprene blends. Journal of Applied Polymer Science 90(14): 4084-4092.

4. Kuriakose A.P. \& Varghese M. (1999). The compounding of nitrile and polychloroprene rubbers with rice barn oil. Iranian Polymer Journal 8(4): 247-255.

5. Kuriakose A.P. \& Rajendra G. (1995). Rice bran oil as a novel compounding ingredient in sulphur vulcanization of natural rubber. European Polymer Journal 31(6): 595-602.

6. Ismail H., Salmiah I. \& Tsukahara Y. (1997). Palm oil fatty acid as an activator in carbon black filled natural rubber compounds: effect of vulcanization system. Polymer International 44: 523-529.

7. Kukreja T.R., Chauhan R., Choe S. \& Kundu P.P. (2003). Effect of the doses and nature of vegetable oil on carbon black/rubber interactions: studies on castor oil and other vegetable oils. Journal of Applied Polymer Science 87(10): 1574-1578.

8. Kundu P.P. \& Kukreja T.R. (2002). Surface modification of carbon black by vegetable oil-its effect on the rheometric, hardness, abrasion, rebound resilience, tensile, tear, and adhesion properties. Journal of Applied Polymer Science 84(2): 256-260.

9. Kundu P.P.(2000). Improvement of filler-rubber interaction by the coupling action of vegetable oil in carbon black reinforced rubber. Journal of Applied Polymer Science 75(6): 735-739.

10. Dasgupta S., Agrawal S.L., Bandyopadhyay S., Chakraborty S., Mukhopadhyay R., Malkani R.K. \& Ameta S.C. (2007). Characterization of eco-friendly processing aids for rubber compound. Polymer Testing 26(4): 489-500.

11. Ismail H. \& Anuar H. (2000). Palm oil fatty acid as an activator in carbon black filled natural rubber compounds: dynamic properties, curing characteristics, reversion and fatigue studies. Polymer Testing 19(3): 349-359.

12. Directive $2005 / 69 / \mathrm{EC}$ of the european parliament and of the council of 16 November 2005. Official Journal of the European Union OJ No. L 323, 9.12.2005, p.51.

13. Boonstra B.B. \& Dannenberg G.M. (1959). Swelling behaviour of rubbers compounded with reinforcing pigments. Rubber Chemistry and Technology 32: 825830.

14. Ohm R.F. (1990). The Vanderbilt Rubber Handbook. $13^{\text {th }}$ Edition. R.T. Vanderbilt Inc., Nowalk, USA.

15. Liyanage S. (2006). Polymer Industries in Sri Lanka. Institute of Chemistry Ceylon, Colombo.

16. Karunanayake L. \& Fernando P.N.J. (2006). Effect of incorporation of peanut and sesame oils and their epoxides on the structure of polyvinyl chloride. Journal of the National Science Foundation of Sri Lanka 34(2): 97-102.

17. Boussoum M.O., Atek D. \& Belhaneche-Bensemra N. (2006). Interactions between poly(vinyl chloride) stabilised with epoxidised sunflower oil and food simulants. Polymer Degradation and Stability 91: 579-584. 